\title{
Trends in Physician House Calls to Medicare Beneficiaries
}

\author{
Lars E. Peterson, MD, PhD, Steven H. Landers, MD, MPH, and \\ Andrew Bazemore, MD, MPH
}

Objective: House calls (HCs) to older adults seemed to be headed for extinction in recent decades. HCs may be a tool to ensure access and reduce institutionalization of the elderly population. This study determines the number and distribution of HCs by physician specialty over time and analyzes associations of providing HCs with physician and area-level characteristics.

Methods: This study was a cross-sectional analysis of 3 complete Medicare Part B claims data for national state-representative samples of physicians in 2000, 2003, and 2006. Multilevel logistic regression determined associations between physician and area-level characteristics and provision of HCs in 2006.

Results: Physicians made 478,088 HCs in 2000; 700,661 in 2003; and 995,294 in 2006. Over the same period, the proportion of physicians making HCs decreased from 7.22 (standard error, \pm 0.20 ) to $5.26( \pm 0.19)$. Physicians in the top decile of HC volume made an increasing number of HCs (median, 56 in 2000 and 86 in 2006). In 2006, physicians who made HCs were more likely to be older, geriatricians, and osteopaths, be in solo practice, and reside in rural areas compared with those who did not make HCs.

Conclusions: Between 2000 and 2006, the number of physician HCs to Medicare beneficiaries more than doubled, whereas the number of physicians making HCs declined. (J Am Board Fam Med 2012;25: 862-868.)

Keywords: Geriatrics, House Calls, Medicare

House calls have been labeled a "vanishing practice" because of trends observed in physician practice patterns. ${ }^{1}$ Although house calls were once a prominent mode of health care delivery, they declined in frequency as medical care increasingly emphasized office- and facility-based services where providers could see a higher volume of patients and new technologies could be centralized. ${ }^{2}$

Recent policy and demographic trends and the changing health care landscape have created an environment favorable for house calls to re-emerge

This article was externally peer reviewed.

Submitted 28 February 2012; revised 18 June 2012; accepted 9 July 2012.

From The American Board of Family Medicine, Lexington, KY (LEP); the VNA Health Group, Red Bank, NJ (SHL); and The Robert Graham Center, Washington, DC (AB).

Funding: none.

Conflict of interest: none declared.

Corresponding author: Lars E. Peterson, $\mathrm{MD}, \mathrm{PhD}$, The American Board of Family Medicine, 1648 McGrathiana Parkway, Suite 550, Lexington, KY 40511-1247 (Email: lpeterson@ theabfm.org). as a viable health care delivery model for frail and functionally limited elderly patients. The aging US population, with a high prevalence of chronic conditions and activity limitations, challenges the financial sustainability and effectiveness of the Medicare program, and new cost-effective care models that support the elderly at home are needed. ${ }^{3}$ The human and financial costs of frequent hospitalization and institutionalization of this vulnerable population has reemphasized the patient's home as a viable site of health care delivery. ${ }^{4,5}$ New mobile diagnostic and information technologies support the practice of medicine in the home in ways previously not possible. ${ }^{6,7}$

The Patient Protection and Affordable Care Act contains several measures that support more physician involvement in home care. ${ }^{8}$ Most notably, the Independence at Home Act was included as a demonstration project that develops a new model of funding physician-led, home-based primary care, with implementation scheduled in 2012.9 Other 
reform initiatives, including accountable care organization pilots ${ }^{10}$ and patient-centered medical home demonstrations, ${ }^{11,12}$ could increase physician involvement in home care management.

These initiatives, plus expansion of insurance coverage, could accelerate the growth in house calls already reported in the literature. ${ }^{13}$ However, previous studies used patient-based samples and failed to fully capture physician practice patterns in providing house calls. The objectives of this study were to (1) assess trends in the numbers of house calls made by physician specialty in 2000, 2003 and 2006 and determine the association between physician and area-level characteristics with (2) the provision of house calls in 2006 and (3) with a physician being in the top decile of house calls made in 2006.

\section{Methods \\ Sample}

We analyzed data containing all Medicare Part B claims for 3 independent and representative crosssectional samples of physicians in 2000, 2003, and 2006. These samples were derived from the American Medical Association (AMA) Masterfile and were created by a single-stage, stratified sample design without replacement to be representative by state. The data analyzed were collected for another study with a sample limited to physicians who graduated from a US medical school and whose major professional activity was providing direct patient care, had a mailing address in one of the 50 states or the District of Columbia, and were at least 1 year beyond terminal residency or fellowship training. Retired physicians, physicians older than 70 years, and those required by law to accept Medicare beneficiaries also were excluded. In addition, we included claims only if they had a payment amount greater than $\$ 0$, the patient was 65 or older at the time of service, and the service occurred in one of the 50 US states or the District of Columbia.

\section{Measures}

We identified house calls as claims with both the place of service as "home" and Current Procedural Terminology codes for evaluation and management services corresponding to house calls for the years 2000, 2003, and 2006 (codes 99341 to 99345 for new patients and 99347 to 99350 for established patients). Ancillary services were identified as services between the same patient and physician on the same date as the house call. The abstracted Medicare claims included patient demographic data, Current Procedural Terminology codes for all services billed during the patient-physician encounter, diagnostic codes from the International Classification of Diseases, 9th Revision, Clinical Modification, and the physician's unique provider identification number.

Physician characteristics were obtained from the AMA Physician Masterfile for each year and were linked with the Medicare claims data using the physician's unique provider identification number. We assigned physician specialty as geriatrics if the primary or secondary specialty was identified among available AMA specialty codes as either "internal medicine geriatrician" or "family medicine geriatrician." We then designated physicians as family medicine, general internal medicine, or general practice if their primary specialty corresponded to one of those AMA specialty codes and they were not previously counted as a geriatrician. Physicians from any remaining specialties were coded as "other." Using claims data, we further characterized physicians who made house calls as high house call physicians if they were in the top decile of house call volume and low house call physicians otherwise.

We obtained additional data on the context of house call delivery by merging claims data with data from the US Census ${ }^{14}$ and Area Resource File $^{15}$ at the level of the county of the physician's primary office location. Two measures represented health care provider availability: the numbers of primary care physicians and total physicians per 10,000 county residents. The proportion of Medicare beneficiaries enrolled in managed-care health plans indicated the level of managed care penetration; higher levels are theorized to lead to an increase in house calls. ${ }^{1}$ We included the elderly proportion of the population (aged 65 and older) to measure the potential demand for house calls. We represented local economic conditions with the proportion of persons within each county with an income below the federal poverty level, which has been shown to influence access to medical care. ${ }^{16,17}$ Previous studies have shown that patients and physicians residing in rural areas were more likely to receive and make house calls, respectively, ${ }^{1,18}$ and we represented urban and rural status using the Office of Management and Budget definitions ${ }^{19}$ for metropolitan, micropolitan, and rural counties. Previous work 
found significant regional variation in the provision of house calls, ${ }^{1}$ and we used the US Census divisions to assess for such variation in the frequency of house calls. Using claims data, we further characterized physicians who made house calls as high house call physicians if they were in the top decile of house call volume and low house call physicians otherwise. We investigated the percentage of house calls in relation to all Part B claims as an indicator of a high house call physician, but we felt that face validity held that the number of house calls made better represents physicians who make house calls a large part of their practice.

\section{Analytic Strategy}

The physician served as our unit of analysis. We computed descriptive statistics for physician characteristics in each of the 3 samples and applied weights for tests of difference and to make population estimates. Then, we evaluated the number and distribution of house calls in total and according to physician specialty. We used hierarchical, or multilevel, logistic regression to assess associations between physician- and contextual-level variables with making a house call and, among physicians making house calls, with being a high versus a low house call physician for the 2006 sample.

We used SAS version 9.2 (SAS Institute, Cary, NC), SAS-callable SUDAAN version 10.0.1 (RTI International, Research Triangle Park, NC), and HLM version 6.0 (Scientific Software International, Skokie, IL) for all analysis, using appropriate weights from our single-stage stratified sampling design. Research approval was granted by the American Academy of Family Physicians Institutional Review Board.

\section{Results}

Our sample sizes were similar across the 3 years studied (Table 1). In bivariate analyses, the physicians who made house calls in each year were more likely to be older; specialists in family medicine, general internal medicine, geriatrics, or general practice; and osteopathic physicians or in solo practice compared with those who did not make house calls. Male physicians were more likely to make house calls in 2000 and 2003 but not in 2006.

The percentage of physicians billing Medicare for at least one house call decreased from $7.22 \%$ to $5.26 \%$ from 2000 to 2006 (Table 2). In all years, geriatricians had the highest percentage of physicians making house calls and "other" physicians had the lowest percentage. However, the total number of house calls increased among all physician groups over the same period. Our sample physicians billed Medicare for 29,619 house calls in 2000, 33,748 house calls in 2003, and 39,157 house calls in 2006 (weighted, this represents 478,088; 700,661; and 995,294 total house calls, respectively, in each year). General internal medicine physicians made nearly half of all house calls in each year, and the number of house calls made between 2000 and 2006 increased among all groups of physicians.

Table 1. Characteristics of Physicians by Provision of House Calls (HCs)

\begin{tabular}{|c|c|c|c|c|c|c|}
\hline & \multicolumn{2}{|c|}{2000} & \multicolumn{2}{|c|}{2003} & \multicolumn{2}{|c|}{2006} \\
\hline & $\begin{array}{c}\text { Any HCs } \\
(\mathrm{n}=2,019)\end{array}$ & $\begin{array}{c}\text { No HCs } \\
(\mathrm{n}=24,546)\end{array}$ & $\begin{array}{c}\text { Any HCs } \\
(\mathrm{n}=1,768)\end{array}$ & $\begin{array}{c}\text { No HCs } \\
(\mathrm{n}=25,254)\end{array}$ & $\begin{array}{c}\text { Any HCs } \\
(\mathrm{n}=1,350)\end{array}$ & $\begin{array}{c}\text { No HCs } \\
(\mathrm{n}=24,584)\end{array}$ \\
\hline Age, mean years (SE) & $48.62(0.27)$ & $47.18(0.07)^{*}$ & $49.75(0.31)$ & $47.98(0.08)^{*}$ & $51.51(0.33)$ & $48.95(0.08)^{*}$ \\
\hline Men $(\%)$ & 86.38 & $81.53^{*}$ & 82.65 & $79.00^{*}$ & 79.49 & 76.92 \\
\hline \multicolumn{7}{|l|}{ Specialty (\%) } \\
\hline Family physician & 33.94 & $12.30^{*}$ & 37.64 & $13.31^{*}$ & 34.64 & $13.07^{*}$ \\
\hline General internal medicine & 34.30 & $13.96^{*}$ & 32.42 & $14.38^{*}$ & 38.18 & $14.53^{*}$ \\
\hline General practitioner & 6.04 & $1.75^{*}$ & 4.82 & $1.24^{*}$ & 4.46 & $0.85^{*}$ \\
\hline Geriatrician & 5.24 & $0.82^{*}$ & 6.38 & $0.88^{*}$ & 8.21 & $1.20^{*}$ \\
\hline Other & 20.47 & $71.17^{*}$ & 18.74 & $70.19^{*}$ & 14.50 & $70.35^{*}$ \\
\hline MD & 89.36 & $94.68^{*}$ & 89.95 & $94.28^{*}$ & 87.20 & $93.73^{*}$ \\
\hline Solo practice & 32.89 & $22.49^{*}$ & 31.13 & $18.71^{*}$ & 31.57 & $18.45^{*}$ \\
\hline
\end{tabular}

Values provided as percentages unless otherwise indicated.

${ }^{*} P<.05$ for within-year comparisons.

SE, standard error. 
Table 2. Weighted Estimated in Trends in House Calls (HCs) by Physician Specialty, 2000-2006

\begin{tabular}{|c|c|c|c|c|}
\hline & 2000 & 2003 & 2006 & $\begin{array}{l}\text { Percent Change } \\
2000 \text { to } 2006\end{array}$ \\
\hline \multicolumn{5}{|c|}{ Providers making at least one HC, \% (SE) } \\
\hline Total & $7.22(0.20)$ & $6.26(0.20)$ & $5.26(0.19)$ & -27.15 \\
\hline Family physician & $17.68(0.78)$ & $15.88(0.76)$ & $12.83(0.73)$ & -27.43 \\
\hline General internal medicine & $16.06(0.75)$ & $13.08(0.73)$ & $12.73(0.75)$ & -20.73 \\
\hline General practice & $21.16(2.25)$ & $20.61(2.82)$ & $22.58(3.54)$ & 6.71 \\
\hline Geriatricians & $33.35(3.49)$ & $32.54(3.43)$ & $27.50(3.10)$ & -17.54 \\
\hline Other & $2.19(0.14)$ & $1.75(0.14)$ & $1.13(0.11)$ & -48.40 \\
\hline \multicolumn{5}{|l|}{ HCs, n $\left(95 \% \mathrm{CI}^{*}\right)$} \\
\hline Total & $478,088(346-611)$ & $700,661(407-995)$ & $995,294(657-1,333)$ & 108.18 \\
\hline Family physician & $117,525(60-175)$ & $95,540(47-144)$ & $173,373(69-277)$ & 47.52 \\
\hline General internal medicine & $211,500(106-317)$ & $389,931(113-667)$ & 438,821 (191-687) & 107.48 \\
\hline General practitioners & $42,476(-1$ to 86$)$ & $62,287(-4$ to 128$)$ & $116,365(-5$ to 238$)$ & 173.96 \\
\hline Geriatricians & $41,811(14-70)$ & $68,022(22-114)$ & $132,774(31-234)$ & 217.56 \\
\hline Other & $64,775(30-99)$ & $84,881(34-136)$ & $133,961$ ( -12 to 280$)$ & 106.81 \\
\hline \multicolumn{5}{|c|}{ Patients receiving HCs, $\mathrm{n}\left(95 \% \mathrm{CI}^{*}\right)$} \\
\hline Total & $164,825(134-195)$ & $218,703(158-279)$ & $282,526(187-378)$ & 71.41 \\
\hline Family physician & $47,972(30-66)$ & $36,628(25-48)$ & $52,869(26-79)$ & 10.21 \\
\hline General internal medicine & $59,993(44-76)$ & $99,052(49-149)$ & $122,833(58-188)$ & 104.75 \\
\hline General practice & $15,127(2-28)$ & $23,221(5-41)$ & $28,574(3-54)$ & 88.89 \\
\hline Geriatricians & $16,149(8-24)$ & $24,331(10-38)$ & $30,597(13-48)$ & 89.45 \\
\hline Other & $25,584(13-38)$ & $35,471(10-61)$ & $47,653(-12$ to 107$)$ & 86.26 \\
\hline
\end{tabular}

*In thousands.

SE, standard error; CI, confidence interval.

Family physicians made the smallest increase in number of house calls (48\%), whereas geriatricians made $217 \%$ more house calls in 2006 than in 2000 . The number of beneficiaries receiving house calls increased by $70 \%$ from 2000 and 2006 (corresponding to 164,825 and 282,526 weighted, respectively).

Investigating the distribution of house call frequency per year among physicians who made house calls, we found that slightly more than half of these physicians made only 1 or 2 house calls in all years. Furthermore, we found that the top decile of physicians making house calls by volume made 25,24 , and $\geq 30$ house calls per year in 2000, 2003, and 2006, respectively (data not shown). The percentage of house calls made by these high house call physicians increased from $74 \%$ to $86 \%$ from 2000 to 2006. The pattern of an increasing concentration of house calls among high house call physicians from 2000 to 2006 held across specialties. The median number of house calls made by high house call physicians increased from 56 (interquartile range, 32-149) in 2000 to 86 (50-373) in 2006, whereas the median among low house call physi- cians rose only slightly, from 1 (1-5) to $2(1-5)$. The median number of patients seen by high house call physicians rose from $20(13-43)$ in 2000 to 29 (15-93) in 2006; the median number of patients seen by low house call physicians was identical in both years: $1(1-3)$.

Established patients received a larger percentage of house calls over the study period, and it increased from $90.24 \%$ to $92.77 \%$. The most common billing diagnoses for house calls over the years studied were hypertension (range, $10.42 \%$ to $17.99 \%$ ), congestive heart failure $(3.65 \%$ to $6.60 \%$ ), diabetes mellitus ( $4.19 \%$ to $4.85 \%)$, chronic obstructive pulmonary disease (2.92\% to $3.02 \%$ ), and Alzheimer disease (1.92\% to $2.14 \%)$. Ancillary services were provided during only a few $(3.70 \%$ to $7.41 \%)$ house calls during the study period. The most frequently provided ancillary service in all years was vitamin B injections (8.81\% to $24.00 \%)$. Other common ancillary services included removing impacted cerumen, joint injections, debridement, phlebotomy, and destruction of premalignant lesions.

Multilevel logistic regression models revealed multiple factors associated with a physician making 
Table 3. Provider and County Characteristics Associated with Making House Calls (HCs) and Being in the Top Decile of Physicians by Volume of HCs Made in 2006

\begin{tabular}{|c|c|c|c|c|c|c|}
\hline & $\begin{array}{l}\text { Any HCs } \\
(\mathrm{n}=1,350)\end{array}$ & $\begin{array}{c}\text { No HCs } \\
(\mathrm{n}=24,584)\end{array}$ & $\begin{array}{l}\text { Adjusted OR } \\
\text { (95\% CI) }\end{array}$ & $\begin{array}{l}\text { High HC } \\
\text { Physicians* } \\
(\mathrm{n}=122)\end{array}$ & $\begin{array}{c}\text { Low HC } \\
\text { Physicians } \\
(\mathrm{n}=1,228)\end{array}$ & $\begin{array}{l}\text { Adjusted OR } \\
\text { (95\% CI) }\end{array}$ \\
\hline \multicolumn{7}{|l|}{ Physician level } \\
\hline Age, mean years (SE) & $51.51(0.33)$ & $48.95(0.08)^{\dagger}$ & $1.03(1.02-1.04)$ & $51.82(0.99)$ & $51.45(0.36)$ & $0.99(0.95-1.03)$ \\
\hline Male sex (\%) & 79.49 & 76.92 & $1.28(1.00-1.62)$ & 76.98 & 79.87 & $0.75(0.33-1.68)$ \\
\hline \multicolumn{7}{|l|}{ Specialty (\%) } \\
\hline Family physician & 34.64 & $13.07^{\dagger}$ & $0.99(0.79-1.23)$ & 22.58 & 36.55 & $0.89(0.40-1.96)$ \\
\hline General internal medicine & 38.18 & $14.53^{\dagger}$ & Ref & 46.25 & 36.94 & Ref \\
\hline General practitioner & 4.46 & $0.85^{\dagger}$ & $1.45(0.78-2.71)$ & 7.33 & 3.96 & $1.19(0.14-10.18)$ \\
\hline Geriatrician & 8.21 & $1.20^{+}$ & $2.41(1.57-3.71)$ & 15.33 & 7.11 & $1.50(0.49-4.54)$ \\
\hline Other & 14.50 & $70.35^{\dagger}$ & $0.08(0.07-0.11)$ & 8.51 & 15.45 & $0.54(0.24-1.20)$ \\
\hline Solo practice & 31.57 & $18.45^{\dagger}$ & $1.48(1.18-1.86)$ & 35.07 & 31.04 & $1.32(0.60-2.89)$ \\
\hline$M D$ versus DO & 87.20 & $93.73^{\dagger}$ & $0.64(0.47-0.89)$ & 85.06 & 87.53 & $0.43(0.15-1.30)$ \\
\hline \multicolumn{7}{|l|}{ County level } \\
\hline $\begin{array}{l}\text { Proportion population } 65 \text { years } \\
\text { or older }\end{array}$ & 13.22 & 12.54 & $1.02(0.99-1.05)$ & 12.54 & 13.33 & $0.94(0.84-1.04)$ \\
\hline Physician-to- population ratio & 28.77 & 31.50 & $0.98(0.97-0.99)$ & 32.74 & 28.15 & $1.03(1.01-1.06)$ \\
\hline PCP-to-population ratio & 10.83 & 11.25 & $1.01(0.97-1.04)$ & 11.05 & 10.80 & $0.89(0.78-1.00)$ \\
\hline $\begin{array}{l}\text { Medicare managed care } \\
\text { penetration rate }\end{array}$ & 13.18 & 14.43 & $0.99(0.98-0.99)$ & 16.05 & 12.74 & $1.01(0.98-1.03)$ \\
\hline $\begin{array}{l}\text { Proportion of population in } \\
\text { poverty }\end{array}$ & 12.34 & 12.85 & $1.00(0.98-1.02)$ & 12.24 & 12.36 & $0.99(0.95-1.04)$ \\
\hline \multicolumn{7}{|l|}{ Rural/urban status } \\
\hline Metropolitan & 82.58 & 89.01 & $0.78(0.57-1.07)$ & 93.62 & 80.79 & $3.05(1.38-6.76)$ \\
\hline Micropolitan & 10.09 & 8.06 & Ref & 2.16 & 11.33 & Ref \\
\hline Rural & 7.38 & 2.93 & $2.54(1.75-3.67)$ & 4.23 & 7.87 & $3.40(1.04-11.09)$ \\
\hline \multicolumn{7}{|l|}{ Region of practice } \\
\hline New England & 8.08 & 6.22 & $2.28(1.52-3.43)$ & 4.26 & 8.67 & $0.41(0.11-1.58)$ \\
\hline Middle Atlantic & 31.56 & 14.96 & $2.08(1.74-2.48)$ & 32.92 & 31.35 & $0.83(0.57-1.22)$ \\
\hline East North Central & 17.73 & 16.63 & $1.56(1.11-2.20)$ & 18.52 & 17.61 & $0.94(0.42-2.07)$ \\
\hline West North Central & 4.88 & 7.35 & $1.05(0.72-1.52)$ & 2.22 & 5.30 & $0.41(0.15-1.14)$ \\
\hline South Atlantic & 13.20 & 19.65 & Ref & 15.43 & 12.85 & Ref \\
\hline East South Central & 3.20 & 6.17 & $0.80(0.52-1.24)$ & 1.03 & 3.54 & $0.34(0.09-1.27)$ \\
\hline West South Central & 5.22 & 9.74 & $0.89(0.56-1.44)$ & 4.30 & 5.37 & $0.58(0.20-1.74)$ \\
\hline Mountain & 4.35 & 6.04 & $1.22(0.81-1.86)$ & 4.25 & 4.37 & $0.92(0.20-4.18)$ \\
\hline Pacific & 11.78 & 13.23 & $1.68(1.03-2.73)$ & 17.07 & 10.95 & $1.07(0.39-2.97)$ \\
\hline
\end{tabular}

*High HC physician is a physician who makes HCs in the top decile of HCs by volume.

${ }^{\dagger} P=<.05$.

Ref, reference category; PCP, Primary Care Physician.

any house call (Table 3). At the physician level, physicians making any house call were more likely to be older (odds ratio [OR], 1.03; 95\% confidence interval $[\mathrm{CI}], 1.02-1.04)$, male $(1.28 ; 1.00-1.62)$, a geriatrician $(2.41 ; 1.57-3.71)$, in solo practice $(1.48$; $1.18-1.86)$, and less likely to be categorized as an "other" specialty $(0.08 ; 0.07-0.11)$ or an allopathic physician (0.64; 0.47-0.89). County-level characteristics associated with a physician making house calls included residence in a rural area $(\mathrm{OR}, 2.54$;
95\% CI, 1.75-3.67) and in the New England, Middle Atlantic, East North Central, or Pacific Census divisions. Physicians were less likely to make a house call in counties with more physicians (OR, 0.98; 95\% CI, 0.97-0.99) and higher Medicare managed care penetration $(0.99 ; 0.98-0.99)$.

In models restricted to house call physicians, no physician characteristic was associated with being a high versus a low house call physician (Table 3). County level characteristics associated with being a 
high house call physician included more physicians per 10,000 county residents (OR, 1.03; 95\% CI, $1.01-1.06)$ and living in a metropolitan $(3.05 ; 1.38-$ $6.76)$ or rural $(3.40 ; 1.04-11.09)$ area compared with a micropolitan area.

\section{Discussion}

From 2000 and 2006, more house calls were made to Medicare beneficiaries by a smaller number of physicians. This trend held across all specialties. Although more than half of the physicians making house calls made only 1 or 2 per year, we found that an increasing number of house calls were made by physicians in the top decile of house calls by volume, our so-called high house call physician group. Our main finding has 2 major implications. First, fewer physicians provide house calls, even as an occasional service. Second, our findings reinforce house calls as an emerging practice model; some physicians emphasize house calls ${ }^{20}$ as a major portion of their practice and a significant primary mode of health care delivery.

Despite using a physician-based rather than a patient-based sample, we found little difference in the personal characteristics of physicians associated with making house calls in comparison with a study using 1993 Medicare data. ${ }^{1}$ Physicians making house calls were still more likely to be osteopathic physicians, primary care physicians, or geriatricians. The advantage of our analysis is that we have complete physician data, whereas prior analyses used data that was only complete for patients, which may miss physicians who made house calls infrequently. A disadvantage of our sampling frame is that we cannot study characteristics of patients in relation to house calls; however, this was not our objective.

Previous work found that patients living in areas with more physicians were more likely to receive house calls; it was theorized that competition was the driving factor of this. ${ }^{1}$ In contrast, we found a negative association between the increasing availability of physicians and physicians making a house call, but we found a positive association between the increasing availability of physicians and a physician being considered a high house call physician. This could be explained by market forces driving physicians to specialize in house calls as a strategy to capture market share, meeting an unmet need, or both. ${ }^{20} \mathrm{We}$ found that few subspecialists, repre- sented as "other," provide house calls. This could be explained by such physicians effectively coordinating care with the primary care physician who is making the house call. An alternative is that nonphysician clinicians working with subspecialists may be making house calls to provide specialty care, which our study would not have captured.

House calls are a part of the American medical ethos, and their resurgence harkens back to the birth of modern medicine. ${ }^{2}$ Medicare could help further speed the resurgence of house calls by promoting demonstration projects along these lines. Also, further research investigating whether receipt of house calls affects health status and health care expenditures is needed.

Our study is not without limitations. First, our data are cross-sectional, and we cannot make statements about any individual physician's practice patterns over time. Second, we captured only house calls billed, and some physicians may perform the service so infrequently that they do so at no charge. Third, as a consequence of our sampling frame, we excluded international medical graduates, nurse practitioners, and physician assistants. Although we have no reason to believe that international medical graduates would be preferentially performing house calls, nurse practitioners are increasingly performing house calls, ${ }^{13}$ and we may be undercounting the total number of house calls. Fourth, we did not include in our analysis and domiciliary house calls to patients residing in assisted living facilities. According to the American Academy of Home Care Physicians, from 2006 to 2009, domiciliary care visits increased as quickly as traditional house calls. ${ }^{21}$ Last, our data were limited to fee-for-service Medicare patients, and it is possible there may be larger growth in house calls among Medicare beneficiaries in health maintenance organizations.

\section{Conclusions}

We found that more house calls to Medicare beneficiaries are being made by fewer physicians. This trend may indicate the emergence of the "home care physician," who harkens back to medicine's roots by delivering care in the ultimate patientcentered medical home, the patient's actual home. Factors possibly influencing the resurgence of house calls are increased payment, an aging population, mobile technology, and a new focus on the patient-centered medical home and accountable 
care organizations. It remains to be seen whether house calls will prove their value to the health care system by providing a much needed service to frail and homebound patients.

\section{References}

1. Meyer GS, Gibbons RV. House calls to the elderly-a vanishing practice among physicians. N Engl J Med 1997;337:1815-20.

2. Starr P. The Social Transformation of American Medicine. New York: Basic Books; 1982.

3. Anderson G. Chronic Care: Making the Case for Ongoing Care. Princeton, NJ: Robert Wood Johnson Foundation; 2010.

4. Landers SH. The other Medical Home. JAMA 2009; 301:97-9.

5. Landers SH. Why health care is going home. N Engl J Med 2010;363:1690-1.

6. Bayne CG, Boling PA. New diagnostic and information technology for mobile medical care. Clin Geriatr Med 2009;25:93-107, vii.

7. Landers SH, Peterson LE, Madigan EA, Xu F, Koroukian SM. Trends in home diagnostic testing for medicare beneficiaries. J Am Geriatr Soc 2007; 55:138-40.

8. Patient Protection and Affordable Care Act of 2009, HR 3590, 111th Cong (2009).

9. The Independence at Home Act of 2009, HR 2560, 111th Cong (2009).

10. Lee TH, Casalino LP, Fisher ES, Wilensky GR. Creating accountable care organizations. N Engl J Med 2010:363:e23.

11. Rittenhouse DR, Shortell SM, Fisher ES. Primary care and accountable care-two essential elements of delivery-system reform. N Engl J Med 2009;361: 2301-3.
12. American Academy of Family Physicians, American Academy of Pediatrics, American College of Physicians, American Osteopathic Association. Joint principles of the patient-centered medical home. March 2007. Available at http://www.medicalhomeinfo.org/ downloads/pdfs/jointstatement.pdf. Accessed September 26, 2012.

13. Landers SH, Gunn PW, Flocke SA, et al. Trends in house calls to Medicare beneficiaries. JAMA 2005; 294:2435-6.

14. U.S. Census Bureau. Small area income and poverty estimates. State and county estimates for 2006. Available at http://www.census.gov/did/www/saipe/ data/statecounty/data/2006.html. Accessed September 26, 2012.

15. U.S. Department of Health and Human Services. Area resource file. Washington, DC: Health Resources and Services Administration; 2007. Available at http://arf.hrsa.gov/. Accessed September 15, 2012.

16. Litaker D, Love TE. Health care resource allocation and individuals' health care needs: examining the degree of fit. Health Policy 2005;73:183-93.

17. Peterson LE, Litaker DG. County-level poverty is equally associated with unmet health care needs in rural and urban settings. J Rural Health 2010;26: 373-82.

18. Cherry D, Burt C, Woodwell D. National ambulatory medical care survey: 2001 summary. Adv Data 2003; $11: 337$.

19. U.S. Census Bureau. Metropolitan and micropolitan statistical areas main. Available at http://www.census. gov/population/metro/. Accessed February 28, 2012.

20. Landers SH, Gunn PW, Stange KC. An emerging model of primary care for older adults: the house call-home care practice. Care Manag J 2009;10:110-4.

21. American Academy of Home Care Physicians. Number of house calls paid by Medicare. Available at http://www.aahcp.org/displaycommon.cfm? an =1\& subarticlenbr=39. Accessed February 28, 2012. 